\title{
ENTRE A RUA E A REDE: UMA ANÁLISE SEMIÓTICA DAS MANIFESTAÇÕES POLÍTICAS CONTEMPORÂNEAS
}

\section{BETWEEN THE NETWORK AND}

\section{THE STREET: A SEMIOTIC ANALYSIS OF CONTEMPORARY POLITICAL DEMONSTRATIONS}

ORIANA DE NADAI FULANETI*

RESUMO: Os protestos ocorridos no Brasil em junho de 2013, desencadeados pelo Movimento do Passe Livre, pertencem a um conjunto de manifestações existentes recentemente no mundo que vem delineando novas formas de ação e interação políticas, com características inovadoras, entre as quais destaca-se a utilização do ciberespaço como parte de sua organização, manutenção e difusão. Nesse contexto, o presente trabalho propõe-se a analisar o funcionamento de um percurso de militância híbrido, um continuum entre a rua e a rede, com o objetivo de verificar qual o papel da rede e o que ela pode revelar sobre essa militância contemporânea. Para isso, analisa-se a página passelivresp no Facebook, perfil oficial do MPL de São Paulo. A base teórica para a investigação é a semiótica

* Docente da UFPB - Universidade Federal da Paraíba. E-mail: od.fulaneti@uol.com.br 
discursiva, mais especificamente a perspectiva das práticas semióticas desenvolvida por Fontanille, proposta de ampliação da abordagem do plano da expressão que possibilita o estudo de todo o percurso militante. Complementarmente, os regimes de interação elaborados por Landowski contribuem para a maior compreensão das novas práticas políticas. Resultados revelam que as ações de rua são apresentadas como práticas intensas, que movem a militância; por sua vez, a rede, com seu potencial, expande e ressignifica essas práticas.

PALAVRAS-CHAVE: Práticas Semióticas. Cibercultura. Movimento do Passe Livre. Política Contemporânea.

ABSTRACT: The protests throughout Brazil in June 2013, triggered by the Free Fare Movement, belong to a wave of demonstrations happening recently in the world that have outlined new ways of actions and political interactions with innovative characteristics. Among them it can be highlighted the use of cyberspace as part of their organization, maintenance and dissemination. In this context, the current study proposes to analyze how a hybrid militant path operates, a continuum between the street and the network in order to verify the role played by the network and what it can reveal about this contemporary militancy. Therefore, it is analyzed the page passelivresp on Facebook, the official profile of FFM of São Paulo. The theoretical basis for the research is the discursive semiotics, more specifically the perspective of semiotic practices developed by Fontanille, a proposal for extension of the plan of expression approach that allows the study of the entire militant path. In addition, Landowski's regimes of interaction contribute to a greater understanding of the new political practices. Results show that street actions are 
presented as intense practices, which move the militancy; in turn, the network, with its potential, broadens and resignifies these practices.

KEYWORDS: Semiotic Practices. Cyberculture. Free Fare Movement. Contemporary Politics.

\section{Introdução}

Observa-se recentemente um crescimento no descrédito do sistema político partidário e o delineamento de novas formas de atuação política, com características distintas daquelas até então existentes. Trata-se de uma militância que vem se construindo e se desenvolvendo entre o real e o virtual, cuja significação apresenta novas formas de expressão e de conteúdo. Podemos, portanto, abordá-la semioticamente.

A Semiótica discursiva, teoria de grande capacidade heurística, já em sua versão inicial, propõe-se a ser uma teoria geral, isto é, reconhecer que o sentido pode ser manifestado por diferentes planos de expressão. Os desdobramentos recentes da proposta greimasiana voltam-se, entre outros, para textos sincréticos, interações, práticas, procurando contemplar os objetos que surgem na sociedade contemporânea. Nessa perspectiva, a proposta deste artigo é estabelecer um diálogo entre semiótica, cibercultura e política, realizando a análise da página do Facebook passelivresp com base nos princípios teóricos da semiótica discursiva. Assume-se, assim, um duplo desafio. Por um lado, testar a metodologia da semiótica na análise de páginas da internet, objeto relativamente novo para os semioticistas; por outro, analisar discursos políticos de movimentos sociais na rede, objeto novo para estudiosos de muitas áreas. 
O discurso estudado aborda, de modo global, o desejo de transformação social. Sujeitos que pretendem mudar a realidade na qual vivem, assunto que não se dissocia do momento histórico, como bem afirma Castells em sua explicação sobre movimentos sociais:

Ao longo da História, os movimentos sociais foram e continuam a ser as alavancas da mudança social. Geralmente se originam de uma crise nas condições de vida que torna insustentável a existência cotidiana para a maioria das pessoas. São induzidos por uma profunda desconfiança nas instituições políticas que administram a sociedade. A conjuminância da degradação das condições materiais de vida e crise de legitimidade dos governantes encarregados de conduzir os assuntos públicos leva as pessoas a tomar as coisas em suas próprias mãos, envolvendo-se na ação coletiva fora dos canais institucionais prescritos para defender suas demandas e, no final, mudar os governantes e até as regras que moldam suas vidas (CASTELLS, 2013, p.161).

Os anos 1960, com o simbólico 1968, foram recheados de protestos em diversas partes do mundo. Esses movimentos foram bastante estudados e retratados, não apenas no meio acadêmico, mas também artístico. Meio século depois, tem-se presenciado novamente uma série de ações reunindo movimentos sociais por diferentes continentes: manifestações no oriente contra regimes opressores e/ou ditatoriais (Primavera Árabe); ocupação de Manhattan em crítica ao capitalismo exacerbado, ato que se reproduz em diversos outros locais dos Estados Unidos e do mundo (Occupy Wall Street e demais Occupys); protestos contra os efeitos negativos da crise econômica espanhola sobre seus cidadãos (Indignados); onda de protestos espalhados pelo Brasil (Jornadas de Junho). Embora alavancadas pelo aumento na tarifa dos transportes na cidade 
de São Paulo, as manifestações ocorridas em nosso país em 2013 desencadearam múltiplas pautas - contra a corrupção; por melhoras na educação e na saúde; contra o país ser sede da Copa do Mundo etc.

Os movimentos do século XXI ainda não foram suficientemente compreendidos, pois além de serem recentes, trazem, mais do que novidades, certas mudanças de paradigmas. Castells (2013), um dos principais estudiosos desses movimentos, aponta algumas semelhanças existentes entre eles: são espontâneos, explosão de uma insatisfação coletiva, e não organizados por instituições políticas; ausência de lideranças, pelo menos do papel do líder representante; múltiplas pautas reivindicativas, mesmo que, na maioria dos casos, tenha havido um desencadeador principal; e, o que mais nos interessa neste texto, movimentos que tiveram o ciberespaço como fundamental para sua organização, difusão e manutenção.

A maioria dos manifestantes é jovem e, fruto de seu tempo, o século XXI, vive em um mundo globalizado, tem a vida inundada por redes sociais, smartphones, tablets e as práticas que acompanham essas tecnologias. São sujeitos que se encontram conectados em redes de múltiplas formas e conciliam confortavelmente o real e o virtual, o on e o off line. Assim, os movimentos sociais contemporâneos, além das características anteriormente mencionadas, são também híbridos, isto é, manifestam-se em espaços urbanos e no ciberespaço.

Sabe-se que o mundo digital encurta as distâncias, possibilita uma comunicação massiva, horizontalizada, relativamente econômica e mais veloz. Imagens e vídeos circulados na internet possuem um grande potencial de sensibilização para determinadas causas. Mas, para além dessas constatações, muitas perguntas ainda precisam ser respondidas: qual o papel da rede nos movimentos sociais contemporâneos? 
Como ela participa e o que ela revela desses movimentos? 0 presente artigo pretende trazer algumas contribuições para responder a essas perguntas da perspectiva da semiótica discursiva.

0 movimento selecionado para nossa investigação é o Movimento do Passe Livre (MPL), um dos principais desencadeadores das Jornadas de Junho de 2013. 0 próprio grupo define-se da seguinte forma: "O Movimento Passe Livre é um movimento social autônomo que luta por um transporte verdadeiramente público, sob controle popular e sem catracas" (MPL, 2013). O MPL foi fundado em 2005 como uma rede federativa de coletivos locais, alguns dos quais já existiam e tinham travado lutas memoráveis, como um protesto ocorrido em Salvador (BA), em 2003, contra o aumento das passagens de ônibus. Ao longo dos anos, apesar da manutenção da causa, seus membros assumem a interdependência entre as diversas pautas de reivindicações sociais, estabelecendo parcerias com outros movimentos, como fica claro na passagem a seguir:

\footnotetext{
O transporte é entendido então como uma questão transversal a diversas outras pautas urbanas. Tal constatação amplia o trabalho do MPL, que deixa de se limitar às escolas, para adentrar em bairros, comunidades e ocupações, numa estratégia de aliança com outros movimentos sociais - de moradia, cultura e saúde, entre outros (Movimento Passe Livre São Paulo, 2013, p.16).
}

De âmbito nacional, o MPL possui diversas páginas na rede social Facebook. Dentre elas, selecionamos para analisar a página de São Paulo (www.facebook.com/passelivresp) por 
ser uma das mais numerosas - possui $301952^{1}$ curtidas - e pela cidade ser uma das que possuem maior problema de mobilidade urbana no país.

Trata-se de um movimento que se comunica também pela rede, com uma linguagem essencialmente multimodal e, comparativamente a movimentos sociais anteriores, possui novas práticas e novos sentidos políticos. 0 foco de nosso estudo recai sobre o percurso de militância que perpassa a rede e a rua; procura-se depreendê-lo e entender a relação que se estabelece entre esses dois espaços. Acredita-se que, assim, será possível obter uma maior compreensão do funcionamento dessa militância política híbrida.

Teoricamente, fazemos uso de dois desdobramentos recentes da semiótica greimasiana para atingir nossos objetivos: o conceito de práticas semióticas, proposta teórica de Fontanille (2005; 2008a; 2008b) que amplia o recorte do plano de expressão, permitindo que o percurso militante seja abordado como um objeto; e as reflexões de Landowski (2014) sobre os regimes de interação, as quais contribuem para a maior compreensão das práticas militantes.

Após essas informações prévias, apresentamos, na próxima seção, algumas noções teóricas importantes para a nossa análise. Em seguida, realiza-se a análise, que se divide em duas partes. Inicialmente, procura-se depreender o percurso militante e o papel da rede ao longo do mesmo; no passo seguinte, enfatizam-se as formas de interação observadas como mais relevantes no percurso. Por fim, tecemos algumas considerações sobre os resultados obtidos.

1 As informações sobre o número de membros da página referem-se ao acesso em $22 / 07 / 2015$. 


\section{Percurso gerativo do plano da expressão}

Fontanille, na introdução de sua obra Pratiques Sémiotiques (2008a), tece algumas considerações sobre o alargamento dos objetos de estudo da Semiótica, seus sentidos e consequências. A teoria greimasiana, ferrenha defensora do princípio da imanência, elege o texto como objeto de análise, opção metodológica bastante conhecida na célebre declaração de Greimas (1974): "fora do texto não há salvação". De acordo com Fontanille, a semiótica discursiva adotou essa postura sobretudo para se diferenciar de análises literárias que buscavam explicar a obra a partir da vida e do contexto dos escritores. Essa restrição do objeto de estudos da semiótica foi, portanto, legítima e necessária no momento de surgimento da teoria. Porém, já há algumas décadas os semioticistas ultrapassaram os limites estritamente textuais ao estudar publicidade, arquitetura, design etc. Exemplo de trabalhos nesse sentido são as análises de Floch (1990) sobre textos sincréticos e de Landowski (1992) sobre as situações semióticas.

Ainda segundo Fontanille, a semiótica, ao expandir suas análises, adota a saída de ampliar o conceito de texto. Assim, a cidade, a música, o mundo sensível, tudo se torna texto. De acordo com o semioticista, é preciso desenvolver reflexões e buscar alternativas no sentido de estender o objeto da disciplina, mantendo o princípio da imanência, considerado essencial para a metodologia semiótica. Sem o princípio da imanência, a teoria narrativa seria uma simples lógica de ação que se aplica a questões narrativas, a teoria das paixões seria apenas uma importação de explicações psicanalíticas, e assim por diante. Desse modo, a proposta do autor é integrar as práticas e as experiências no objeto, depreendendo, para a 
análise, diversos planos de imanência. 0 pesquisador francês enfatiza que isso não significa colocar um objeto de análise no contexto, mas tornar o contexto parte da análise.

A preocupação de Fontanille vai ao encontro da expansão das tecnologias da informação e das formas de comunicação, as quais resultam em novas práticas e objetos que precisam ser analisados, com destaque para a cibercultura. A comunicação em rede vem trazendo mudanças no modo de interação e na linguagem, motivo que nos leva a adotar a perspectiva das práticas semióticas para a realização da análise de uma página do Facebook.

Assim como a proposta de Greimas para a análise do plano de conteúdo divide-se em patamares, no caso, os níveis fundamental, narrativo e discursivo, Fontanille também propõe níveis de pertinência do plano de expressão. Esses níveis da expressão podem ser descritos em uma sintaxe local, levando-se em consideração os elementos do próprio nível, ou analisados na relação com os demais níveis, na sintaxe global. Dessa forma, um mesmo elemento poderá cumprir diferentes funções actanciais, ou diferentes papéis modais, passionais, temáticos etc. de um nível para outro.

O primeiro nível, aquele das unidades mínimas - signos ou figuras, consiste na abordagem unicamente do signo, a apreensão de uma experiência figurativa. Este signo poderá ser verbal, visual, sonoro, verbo-visual etc. 0 segundo nível - textos-enunciados, engloba um conjunto de unidades que formam uma totalidade que se interpreta, dotada de intencionalidade, ou seja, aborda-se o texto enquanto enunciado, considerando-se, portanto, a enunciação. Fontanille (2005) chama a atenção para a incorporação de uma dimensão plástica nas imagens quando da passagem do primeiro para o segundo nível. Ou seja, quando o nível de pertinência é a 
figura, o elemento sensível da imagem é abordado como parte da substância da expressão; por outro lado, ao se abordar o nível do texto-enunciado, os elementos sensíveis e materiais da imagem passam a afetar também as formas do conteúdo.

A página estudada possui signos de diferentes linguagens, que se manifestam sobretudo em textos escritos, fotos, vídeos, músicas, cartazes, tirinhas e charges. As cores predominantes são escuras, muito preto e cinza em fundo branco, com a presença, às vezes, do vermelho como marca de luta. Os textos difundidos pela página são curtos, produzidos essencialmente na forma padrão da Língua Portuguesa, sem gírias ou marcas de oralidade.

0 texto-enunciado encontra-se disposto em um suporte ou veículo e, para considerá-los na análise, é preciso ampliar a pertinência para a semiótica dos objetos. Os objetos, terceiro nível de pertinência, são elementos com certa homogeneidade de forma ou função que, em seu conjunto, destinam-se a determinados usos ou práticas. Um exemplo seria um livro ou um cartaz. 0 nível dos objetos é aquele dos corpos materiais.

Na rede, acessamos diversos objetos: um CD, um filme, um cardápio, um mapa, um livro, um cartaz e até mesmo a página de uma rede social. Não é à toa que a rede é também conhecida como realidade virtual, pois ela contém em seu interior toda uma cultura, a cibercultura. A página do MPL no Facebook funciona como um suporte que abriga diferentes gêneros, dentre os quais destacam-se postagens, comentários, fotos, vídeos, artigos e reportagens, podendo ser encontrados, ainda, desenhos, trechos de filme, de jornais impressos etc.

A experiência de interagir com o texto-enunciado por meio do objeto consiste em uma prática, uma das noções centrais do percurso. Esse nível abrange "[...] todos os elementos 
necessários à produção e à interpretação da significação de uma interação comunicativa" (FONTANILLE, 2005, p 24).

A abordagem da prática expande a configuração temporal, espacial e actancial, à medida que não se consideram mais apenas essas categorias no texto-enunciado, mas em seu uso, isto é, observa-se o tempo do uso, o espaço do uso, a relação entre actante e texto etc. Vale ressaltar que um mesmo objeto pode ser usado de diferentes maneiras, por exemplo, um canivete pode ser usado para cortar, raspar etc. Nossa análise debruça-se essencialmente sobre textos-enunciados que textualizam as práticas vivenciadas pelo grupo, entre as quais predominam o próprio uso da página, manifestações, atos, aulas públicas e debates.

A conjunção, orquestração, gestão de diversas práticas em uma unidade significante produz estratégias. "A dimensão estratégica resulta, portanto, da conversão em dispositivo de expressão de uma experiência de conjuntura e de ajustamento entre cenas predicativas práticas" (FONTANILLE, 2005, p.27, grifo no original). A estratégia ocupa-se da programação de percursos de práticas e das possíveis intersecções existente entre elas.

Por fim, o último nível, as formas de vida. Para explicá-lo, Fontanille recorre a um estudo feito por Floch, no qual este propõe uma tipologia com quatro categorias de usuários do metrô: caminhadores, profissionais, flâneurs e sonâmbulos. Assim, dependendo do objetivo final, da maneira como se relaciona com o lugar, o usuário tem um comportamento, uma forma de vida ou éthos. Trata-se de um modo de se relacionar não apenas com uma situação particular, mas com todo um conjunto de situações e de estratégias, produzindo estilos, os chamados estilos estratégicos. Tomando o exemplo da classificação dos usuários do metrô, é possível generalizar os 
estilos estratégicos por critérios de identificação e classificar também o modo de navegação virtual, de frequentar o supermercado, entre outros.

De acordo com o que foi apresentado, o movimento pela tarifa zero poderia ser considerado em si uma forma de vida. Entretanto, em nossa análise, estamos classificando o MPL como um movimento estratégico, a militância pelo transporte, em contraposição ao formato de militância de um partido político, que converge questões de diversos temas, e estamos classificando-o aqui como uma forma de vida. Para tentar justificar nossa escolha, vale voltar às palavras do autor:

A caminhada intermitente, o passeio, o sonambulismo e o profissionalismo são, portanto, formas típicas extraídas das estratégias de ajustamento entre o percurso próprio do usuário e as restrições, as proposições e os obstáculos que caracterizam o conjunto das zonas críticas do itinerário (FONTANILLE, 2005, p. 29, grifo no original).

Do ponto de vista do plano da expressão, uma forma de vida é a deformação corrente, obtida pela repetição e pela regularidade do conjunto das soluções estrategicamente adotadas para ajustar as cenas predicativas entre elas. (FONTANILLE, 2005 , p. 30, grifo no original).

A depender do recorte feito para o conjunto de soluções, pode-se perfeitamente ter um sujeito sonâmbulo no transporte e profissional no trabalho. 0 projeto político-partidário predominante no século XX investia em um modelo de sociedade, com propostas para transporte, saúde, educação, tecnologia, enfim, todos os âmbitos sociais.

A forma de interação entre os diferentes níveis de pertinência ganha profundidade na análise, quando levamos em consideração as categorias desenvolvidas por Landowski 
(2014). Preocupado em captar o sentido "em ato", em sua situação de construção, Eric Landowski dedica-se essencialmente às interações, consideradas a essência da construção social dos sentidos. Em seu trabalho As interações arriscadas (2014), o autor propõe uma nova tipologia das interações, dividida em quatro regimes: programação, manipulação, ajustamento e acidente.

O regime de programação está ligado aos programas narrativos mais simples e comuns, podendo ser entendido como aquele das regularidades, do esperado. Trata-se, por exemplo, da relação que se estabelece entre o homem e uma máquina por ele programada, como o ato de ligar um computador ou instalar um programa.

O segundo regime, de manipulação, foi muito explorado na teoria semiótica. De modo geral, tem-se um destinador-manipulador que procura convencer o destinatário a fazer o que ele lhe propõe. Trata-se de uma forma de interação que envolve as competências modais do destinador e do destinatário. Assim, não existe garantia pré-determinada de sucesso na manipulação (até porque o destinatário pode recusá-la), o que faz com que haja uma certa imprevisibilidade em seu resultado, pois envolve sistemas de valores, interpretações, preferências e gostos distintos do destinador e do destinatário. Em outras palavras, para persuadir o destinatário, o destinador precisa conhecê-lo minimamente. As interações entre o internauta e aqueles que publicam e ou produzem no ciberespaço são, em grande medida, de manipulação, pois o objetivo de muitos sites é fazer o usuário prosseguir navegando.

No regime de ajustamento, o destinador deixa de ser referência central na manipulação. Dessa forma, os actantes em interação se ajustariam entre si e desse ajustamento surgiriam novos sentidos, sentidos não esperados. Não haveria, 
nesses casos, mais uma apropriação do mundo por um sujeito conhecedor, mas por um sujeito que sente, acima de tudo, na interação com o mundo e com outros sujeitos por meio dessa interação. 0 ajustamento é definido pelo autor como uma construção recíproca entre sujeitos ou entre sujeitos e objetos, isto é, como parceiros na interação. As trocas virtuais, como bate-papo ou recados em sites são potenciais espaços para a interação em regime de ajustamento.

Em relação ao acidente, Landowski o define como, primeiramente, um risco puro, no qual todos os valores envolvidos em uma interação são embaralhados. Essa definição de acidente se aproxima mais do que entendemos ser acidentes naturais, como uma enchente, um tornado ou um terremoto. Mas o autor apresenta uma segunda acepção de acidente, a de um risco limitado produzido por um actante. Nesse caso, surge a figura de um destinador que não propõe mais um contrato nem exige algo em troca e que, portanto, não se comunica com os sujeitos, mas apenas os julga sem justificar suas decisões, fazendo surpresas para o outro, que podem ser negativas ou positivas.

\section{Percurso de militância}

A análise da página passelivresp permite depreender um percurso de militância, deixando algumas passagens explicitamente marcadas e outras apenas pressupostas. Esse percurso se constitui das seguintes etapas: recorte da realidade, decisão e organização da intervenção, intervenção e sanção. Trata-se de uma sequência que se revela extremamente semelhante ao esquema narrativo canônico proposto por Greimas - manipulação, competência, performance e sanção. 
0 que estamos chamando de recorte da realidade consiste na divulgação da denúncia de algo do cotidiano por meio de texto escrito, foto, vídeo e, na maioria das vezes, todos os recursos conjuntamente. Entre as diversas experiências vivenciadas pelo sujeito em seu cotidiano, algumas são selecionadas para serem destacadas e, com o caráter hipermidiático da página, o apelo multissensorial torna-se maior, o que possibilita que a notícia sensibilize mais:

1. Em outubro de 2013, a SPTrans tirou de operação a linha 577T/Vila Gomes - que atendia a região do Butantã, ligando-a à Paulista e à zona sul. Esse corte de linha não é um caso isolado... (trecho de notícia "Pela volta da linha 577T! Moradores da Vila Gomes se mobilizam, publicada em 04/02/2014).

2. Nas últimas semanas os jornais noticiaram que uma mulher foi estuprada em um dos pontos mais movimentados da cidade de São Paulo. A garota de dezoito anos trabalhava em uma cabine de recarregamento de bilhete na estação República do metrô e estava saindo do trabalho. [...] Os valores da tarifa que excluem milhares de pessoas do acesso à cidade estavam protegidas. As trabalhadoras, não. (trecho da NOTA DAS MULHERES DO MOVIMENTO PASSE LIVRE A RESPEITO DO ESTUPRO NO METRÔ REPÚBLICA, postada em 22/04/2015).

O tema predominante aborda os problemas no transporte público da cidade de São Paulo - o aumento da passagem, o corte de linhas, a superlotação, a espera prolongada, entre outros. Entretanto, há também denúncia e solidariedade em relação a outras causas, prioridades de outros movimentos sociais, como a violência contra as mulheres, movimento de moradia, greves de diferentes categorias etc. Os valores mais combatidos encontram-se revestidos semanticamente como 


\section{opressão, autoritarismo, corrupção, preconceito, machis- mo, homofobia e discriminação.}

De modo geral, depreende-se na página a voz de um sujeito insatisfeito, indignado com a sua realidade, que quer intervir e agir. As postagens de críticas e denúncias contribuem para a construção de um mesmo julgamento e, sobretudo, uma mesma percepção da realidade. 0 sujeito busca, com isso, indignar também os seus enunciatários. A rede participa dessa etapa como um instrumento de manipulação que sensibiliza as pessoas para os problemas cotidianos, e como meio de divulgação de notícias.

Os recursos sincréticos viabilizados pela hipermídia constroem uma manipulação que não se produz apenas com recursos argumentativos lógicos e racionais, mas também, e principalmente no caso dessa página, com recursos sensoriais. Nesse sentido, a identificação ocorre porque o internauta concorda com os argumentos ou discorda deles, mas também pelo reconhecimento dos recursos fotográficos, musicais, cromáticos, que permitem com que ele se imagine parte daquela cena apresentada, inserido naquele contexto, membro daquela comunidade. As dimensões de alcance variam de uma postagem para outra. Por exemplo, o segundo trecho anteriormente replicado foi curtido por 3969 pessoas e compartilhado por 2259. Sabe-se que o número de curtidas é sempre inferior ao número de pessoas que veem a postagem e, por outro lado, uma postagem compartilhada amplia consideravelmente o raio de atuação da mesma.

A segunda etapa - decisão e organização de intervenção - encontra-se mais pressuposta do que marcada. A página estudada não funciona como espaço consultivo ou deliberativo, apenas como meio de divulgação que convoca o internauta a participar do ato ou de sua organização. 0 que se 
tem normalmente são textos de recorte da realidade acompanhados de um chamado para a (re)ação. 0 movimento revela, com isso, o objetivo de pautar a própria prática cotidiana, não ser sucumbido pela experiência, mas interferir nela:

3. ATO HOJE: CONTRA A VIOLÊNCIA DA TARIFA E DA POLÍCIA! ${ }^{2}$ Ás 17:30h na Estação Santo André, em repúdio ao linchamento de um passageiro pelos seguranças da CPTM, o movimento passe livre abc convoca uma mobilização! (Trecho de nota veiculada em 07/05/2014)

4. Nas próximas semanas, a Prefeitura começará um grande Processo de mudanças no transporte coletivo da capital. 0 que for decidido na próxima licitação de transporte [...] vai decidir um monte de coisa importante para quem usa o ônibus todo dia: quais linhas vão ser cortadas, qual a frequência das linhas, a lotação dos ônibus e, também, o valor da tarifa e seus aumentos. Você sabia de tudo isso?

Venha discutir com a gente essas mudanças, e se organizar para dizer que não aceitamos mais que o lucro dos empresários dos transportes esteja acima dos interesses da população! (Trecho de nota veiculada em 19/03/15).

As intervenções, também chamadas pelo movimento de ação direta, terceira etapa do percurso militante, ocorrem essencialmente fora da rede. Entre as mais mencionadas na página, têm-se: manifestações; atos (travar avenidas; acorrentar-se em prédios; interromper aulas etc.); debates; aulas públicas; seminários; saraus e shows de cultura popular; bingos e rifas para arrecadar dinheiro; participação em atos de movimentos parceiros. Há também, embora em menor quantidade, a menção a algumas intervenções que se realizam totalmente pela rede: petições virtuais, pressionando políticos via e-mail,

2 Vale ressaltar que dias antes desta convocação o movimento postou fotos e vídeos que mostravam seguranças agredindo um passageiro. 
e abaixo-assinados. 0 relato das intervenções consiste no principal conjunto de textos presente na página estudada.

As ações presenciais são supervalorizadas e existe até uma categoria pejorativa para nomear aqueles que fazem críticas na rede, mas não participam de ações, os ativistas de sofá. Entretanto, não há na página críticas ou xingamentos por parte do MPL aos cidadãos que não são militantes. A manipulação ocorre essencialmente por tentação, não havendo provocação ou intimidação.

A última etapa - sanção, de modo geral atribui apreciação positiva às ações militantes, muitas vezes apresentando o balanço de conquistas obtidas por meio da luta reivindicativa.

5. Só a luta muda a vida!

0 azulzinho não voltou, mas a viagem aumentou

0 povo da Vila Gomes se organizou e conseguiu uma linha que faça o trajeto até a Paulista. [...] Toda força àqueles que lutam! Agora é o povo quem vai mandar nos transportes! (Trecho da notícia "Só a luta muda a vida", postado em 05/05/2014).

6. Ontem, várias mulheres se solidarizaram com as vítimas diárias de abusos no transporte público, e realizaram uma ação direta nos metrôs Sé, República e Brás, onde aconteceu o caso do dia 27. Várias usuárias manifestaram apoio e relataram casos em que foram ou conheciam as vítimas.

A mobilização das mulheres mostra que abusos não serão mais tolerados, que haverá revide e que não ficaremos caladas, nem aceitaremos ser culpabilizadas pelo comportamento machista de alguns (vários) homens de nossa sociedade. CONTRA TODAS AS CATRACAS, INCLUSIVE AS DO MACHISMO. MEXEU COM UMA, MEXEU COM TODAS! (Trecho da nota "Contra os abusos no transporte público", postada em 03/06/2015).

Os valores positivos mais enfatizados, aquilo pelo que se 
luta, são solidariedade, união, respeito, autonomia, dignidade, direito, igualdade, tolerância e coragem.

Os elementos que permanecem ao longo do percurso podem ser considerados um fator de coesão, constitutivo da identidade do movimento. Reconstituindo o percurso militante presente na página, tem-se um sujeito, preenchido semanticamente por MPL e também por movimento do passe livre, movimento tarifa zero, povo, trabalhadores, população, periferia, moradores de bairro que, modalizado pela indignação, decide fazer alguma coisa. Essa decisão é fruto de sanção às práticas dos que são apontados como inimigos, sendo os mais presentes governos, Estado, prefeitura, poder público, políticos, corruptos, capitalistas, empresas de ônibus e empresários. 0 que não se tolera mais é o capitalismo exacerbado, que causa diferenças e prejuízos; a corrupção, e o atual modelo de política, que tem a imagem bastante desgastada. A ação do sujeito, ao ser textualizada, replicada e sancionada positivamente, traz a esperança, a crença de que é possível fazer alguma coisa e obter alguma transformação. 0 percurso vai do querer fazer (estimulado pela indignação) ao crer poder/dever fazer (estimulado pela esperança), centrado sempre nas pautas do transporte público da cidade de São Paulo.

Observa-se que a rede funciona como uma espécie de metonímia do movimento, por meio da página é possível reconstruir muito de sua atividade cotidiana. A página foca mais nas duas últimas fases, a prática (performance) e a sanção. Os textos remetem essencialmente às ações, sejam as que deverão ser realizadas ou as que foram realizadas. Não se encontram muitas exposições teóricas, construções de propostas, apresentação de informações baseadas em dados quantitativos etc., embora muitas das ações convocadas correspondam 
à participação em debates e discussões. 0 elemento essencial, mais valorizado, mais textualizado, reside nas práticas que ocorrem fora da rede, as quais correspondem ao elemento intenso dos textos-enunciados. As postagens, sejam reprodução da ação ou sanção das mesmas, partem do elemento mais intenso para o mais extenso, da emoção para a racionalização.

Mas, por que a intensidade recai mais sobre as práticas? A verificação das possíveis variáveis presentes na interação de cada uma das etapas do percurso militante contribui para algumas explicações a esse respeito.

0 recorte da realidade depende, obviamente, de acontecimentos da conjuntura, mas é o momento inicial do programa, a função do sujeito é apenas selecionar, entre as experiências existentes, aquelas sobre as quais vale ou não a pena opinar, intervir. Provavelmente os membros envolvidos nesse processo de escolha são poucos. Poderá haver discordância entre eles, mas os regimes de interação predominantes são certamente a manipulação e a programação.

De modo semelhante, a organização de um evento tem toda uma logística envolvendo, por exemplo, o local (preocupações com o espaço, a segurança, o acesso), o material necessário (cartazes, megafones, aparelhos fotográficos etc.), os protagonistas (palestrantes, debatedores, músicos etc.), a captação de recursos (se for o caso). Entretanto, trata-se da etapa do planejamento e, mesmo havendo dificuldades e imprevistos, predomina a racionalização da ação, que é feita com a participação apenas de alguns membros do MPL.

A partir do momento em que a ação se inicia, ampliam-se os horizontes espaciais e actanciais, além de o ritmo sair do controle do grupo. Uma intervenção não conta apenas com membros do MPL, ela acontece na rua ou em algum espaço público, ganha adeptos e contrários diversos, encontrando-se, 
portanto, muito mais sujeita ao acidente e à necessidade de ajustamentos. Essas formas de interação são mais intensas, provocam paixões intensas e produzem adrenalina. Como um acidente, seus resultados também são imprevisíveis. Poderá ser um sucesso, conquistar a simpatia da opinião pública, a adesão de algum movimento novo; ou poderá ser um fracasso, resultar em inúmeros militantes presos, ou em cidadãos insatisfeitos com o trânsito causado. Correm-se riscos.

Verifica-se por meio dessa análise que, no caso do MPL e dessa página do face, a intensidade está fora da rede. Entretanto, a rede possui um grande potencial de replicar as ações diretas, expandindo-as e redimensionando-as. Seja com a postagem ao vivo, que expande as fronteiras espaciais, permitindo que pessoas de diversos lugares tenham acesso ao que está acontecendo; seja com postagens posteriores de fotos, vídeos e comentários, repercutindo a ação e prolongando seu efeito. Além disso, os sujeitos podem participar como personagens da ação e como produtores de relatos das intervenções, o que torna o sentido dessas práticas potencialmente diferente daquelas nas quais os sujeitos participavam, mas não eram registrados como atores, ou eram, em muito menor escala.

\section{Práticas de navegação e estratégias políticas}

Até agora, foi feita uma abordagem do percurso e das práticas militantes do ponto de vista do perfil oficial da página. Contudo, por meio dos comentários, é possível depreender outras maneiras de usar o mesmo objeto, outras práticas. Além do dono do perfil, aquele que alimenta a página e posta os textos mencionados, existem outras formas de participação. 0 sujeito diante da página poderá ser apenas um leitor, 
realizar uma participação tímida, curtindo ou compartilhando algo, ou participar mais ativamente por meio de comentários. No caso da página do MPL, existem muitos comentários, favoráveis e contrários ao grupo. Trata-se, portanto, de um espaço privilegiado para a depreensão da heterogeneidade dos movimentos sociais.

No dia dezenove de junho de 2015, o movimento postou um texto intitulado "Dois anos atrás barramos o aumento", o qual discorria sobre a vitória obtida com as manifestações de junho de 2013. Como respostas à postagem surgem muitos comentários. Alguns totalmente favoráveis, em apoio, geralmente agradecendo pelo incentivo ao espírito de luta e pelas conquistas obtidas pelo movimento, como o Passe Livre Estudantil e a revogação do aumento da tarifa. Outros comentários são totalmente contrários, desqualificam o movimento, sobretudo por meio de críticas morais: vagabundos, covardes, vendidos. Por fim, um último grupo de comentários revela os nem totalmente favoráveis nem totalmente contrários:

7. Esse movimento já era! Realmente a luta foi por apenas 0,20 $\mathrm{R}$ \$. Iniciaram uma grande mobilização mas não deram continuidade, ganharam uma batalha mas perderam a guerra, cadê as mobilizações ou ao menos a opinião de vcs hj q foi um dia de extrema importância para a nação, a votação de uma lei onde $90 \%$ da nação é a favor foi reprovada, a conta de luz sobe pela terceira vez esse ano a partir de sábado, o gigante dormiu de novo! (DM, 01/07/2015) ${ }^{3}$.

8. 0,20 centavos vcs fizeram um alarde e por 0,50 nem protesto no facebook teve. Eu estive em 2013 mas me arrependo. Vocês acham que provaram alguma coisa? 0 aumento de 0,50 prova que a ida as ruas não deu em nada. Foi apenas fogo de

3 No intuito de preservar a identidade de quem comentou, divulgamos apenas as iniciais do perfil e a data da postagem. 
palha e apagou faz tempo. (RZ, 19/06/2015).

9. Cadê vocês??? O Brasil está despencando ladeira abaixo e vocês contando vantagem, ao invés disso usem o seu poder, mobilizem a população, e vamos fazer valer a frase: não é pelos $\mathrm{R} \$ 0,20$, acredito que queremos muito mais do que transporte público acessível (FC, 19/06/2015).

Nesses comentários há o reconhecimento de que o movimento foi importante em 2013, entretanto, os acontecimentos posteriores produzem uma releitura dessa importância. Alguns continuam confiando no MPL, sugerindo melhoras; outros perderam a confiança no movimento e declaram arrependimento de ter participado da luta, sentem-se enganados, manipulados. Entre as principais críticas encontram-se o aumento de 0,50 centavos na tarifa de ônibus ocorrido em 2015; a necessidade de expansão da pauta - aumento da energia, inflação, corrupção, problemas na saúde etc.; e o fato de o MPL ter encerrado as jornadas de junho após ter conseguido, em negociação com o governo, barrar o aumento da tarifa.

Apesar das críticas, observa-se que o MPL é reconhecido como liderança, um grupo visto com poder de mobilizar as pessoas (exemplo 9), um grupo de quem se espera pronunciamento (exemplo 7). É interessante observar também que o Movimento do Passe Livre tem sua pauta específica e não deveria ser cobrado por aquilo a que não se propõe, mas, por ter se tornado um movimento amplo, passa a absorver outras demandas. 0 reconhecimento da liderança e a concentração de pautas em um só movimento parecem contrariar as tendências dos movimentos sociais contemporâneos, mostrando que vivemos um momento de transição, de construção de uma imagem da forma ideal de se fazer política.

Existem várias formas de participar, várias maneiras de interagir, o que significa que os usuários da página podem 
fazer parte de outros percursos militantes ou simplesmente estar sob outra estratégia, não necessariamente militante. Esse fenômeno visivelmente aconteceu nas Jornadas de Junho quando uma mesma prática, a manifestação, reuniu diferentes estratégias e diferentes formas de vida. Expressões como "iniciaram uma grande mobilização" (exemplo 7), "foi apenas fogo de palha" (exemplo 8) mostram um sentimento inicial de satisfação com os atos políticos. Todavia, com o fim das jornadas, o descontentamento voltou, como bem afirma Zizek:

[...] não existe um único objetivo "real" perseguido pelos manifestantes, algo capaz de, uma vez concretizado, reduzir a sensação geral de mal-estar. 0 que a maioria dos manifestantes compartilha é o sentimento fluido de desconforto e descontentamento que sustenta e une demandas particulares. (ZIZEK, 2013, p.103).

As Jornadas de Junho representam um exemplo de acontecimento na intervenção. O MPL chamou para uma ação contra o aumento da tarifa, mas o desejo de protestar estava latente em várias pessoas, o campo era fértil, e as manifestações se espalharam. À estratégia da luta pelo transporte, somaram-se luta por saúde, moradia, educação e as mais diversas reivindicações. Protestar tornou-se uma competência modal para estratégias de vários movimentos, mas também uma performance em si.

Esse breve estudo das interações existentes na página passelivresp revela que a expectativa com o movimento é variável de uma pessoa para outra, mas que elas estão insatisfeitas e, em grande medida, experimentaram um prazer de ter participado de uma ou várias manifestações políticas. 


\section{Práticas semióticas, cibercultura e práticas militantes}

A abordagem de diferentes níveis de pertinência da expressão possibilitou, por meio do estudo predominante de textos-enunciados sincréticos, a depreensão de um percurso de militância do Movimento Passe Livre. De forma complementar, os diferentes regimes de interação permitiram uma maior compreensão das expectativas e das paixões envolvidas nessa militância contemporânea que vem se delineando.

Esse percurso de militância é híbrido, conectando a rua e a rede em sua composição. A rede participa de todas as etapas, expandindo as fronteiras espaciais e actanciais, acelerando o ritmo do movimento. Mas as ações mais valorizadas, mais textualizadas, mais intensas, encontram-se fora do mundo virtual. Essas ações funcionam como um elemento de coesão, construindo uma comunidade de sujeitos que se identificam pelas dificuldades experienciadas no cotidiano, pela cultura popular ou por participarem de atos políticos. Um movimento movido por ações alimentadas e expandidas na rede.

Fontanille (2008b, p.30-31), discorrendo sobre a integração entre os níveis, apresenta a noção de integração descendente ou condensação, quando há projeção de um nível superior sobre um nível inferior. Como exemplo, traz o ato de rezar, uma prática que condensa em si toda uma forma de vida, o éthos cristão. Nesse caso, inversamente, os movimentos sociais contemporâneos reúnem em suas práticas sujeitos com estratégias e formas de vida diversas. Verifica-se, portanto, um delineamento maior, ou mais coeso, na expressão do que no conteúdo.

Paulo Arantes, em entrevista concedida ao jornal $O E S-$ 
tado de São Paulo 4 a respeito das Jornadas de Junho, afirma que foram "protestos desengajados, [...] quando protestar se tornou uma questão estritamente pessoal, e o ativismo, a rigor, um estilo de vida". Diria semioticamente que as novas formas de manifestação são práticas que revelam o desejo de construção de uma nova forma de vida. Práticas com desejo de transformação social.

\section{REFERÊNCIAS}

CASTELLS, M. Redes de indignação e esperança: movimentos sociais na era da internet. Trad. Carlos Alberto Medeiros. Rio de Janeiro: Zahar, 2013.

FONTANILLE, J. Significação e visualidade: exercícios práticos. Trad. Elizabeth Bastos Duarte e Maria Lília Dias de Castro. Porto Alegre: Sulina, 2005.

FONTANILLE, J. Práticas Semióticas: imanência e pertinência, eficiência e otimização. Trad. Maria Lucia Vissotto et al. In: DINIZ, M. L.V.P; PORTELA, J.C. (Org.). Semiótica e mídia: textos, práticas e estratégias. Bauru: UNESP; FAAC, 2008b, p. 15-74.

FONTANILLLE, J. Pratiques Sémiotiques. Paris: Puf, 2008a.

FLOCH, J-M. Sémiotique, marketing et communication: sous les signes, les strategies. Paris: PUF, 1990.

4 Entrevista concedida por Paulo Arantes a Ivan Marsiglia sob o título "O futuro que passou", publicada no jornal O Estado de São Paulo, em 22/06/2013. 
GREIMAS, A. J. L'Énonciation: une posture épistémologique. Significação - Revista Brasileira de Semiótica. Centro de Estudos Semióticos A. J. Greimas, Ribeirão Preto, n. 1, p. 09$25,1974$.

LANDOWSKI, E. Interações arriscadas. Trad. Luiza Helena de O. Silva. São Paulo: Estação das Letras e Cores, 2014.

LANDOWSKI, E. A sociedade refletida. Trad. Eduardo Brandão. São Paulo: Educ, 1992.

MOVIMENTO PASSE LIVRE - SÃO PAULO. Não começou em Salvador, não vai terminar em São Paulo. In: MARICATO, Ermínia etal.Cidades rebeldes. Passe Livre e as manifestações que tomaram o Brasil. São Paulo: Boitempo, 2013. p. 13-18.

ZIZEK, S. Problemas no paraíso. In: MARICATO, Ermínia et al. Cidades rebeldes. Passe Livre e as manifestações que tomaram o Brasil. São Paulo: Boitempo, 2013. p. 101-108.

Artigo recebido em setembro de 2015 e aprovado em dezembro de 2015.

Disponível em: http://seer.fclar.unesp.br/casa 